\title{
Teachers' Stage of Concern in Constructing Lesson Plan of Elementary School
}

\author{
Badeni \\ Faculty of Teacher Training and Education \\ Bengkulu University \\ mbmbadeni@gmail.com or badeni@unib.ic.id
}

\author{
Wachidi \\ Faculty of Teacher Training and Education \\ Bengkulu University \\ wachidipawiro@gmail.com
}

\begin{abstract}
The purpose of this study was to describe of teacher' stages of concern in constructing lesson plan. The approach used in this study was a descriptive study. The number of population of this study were $\mathbf{5 0 0}$ primary school teachers. Meanwhile, the research sample were 50 teachers. A random sampling technique in the form of the lottery was used to get samples. Data were collected, classified, processed and analyzed by using the norms of the group in the calculation of percentile. The findings of this study were eight teachers $(16 \%)$ in a stage of concern called at the stage of 0 (stage of awareness), nine teachers (18\%) have a stage of concern at the level of $I$ (stage of information); eight teachers (16 percent) have a stage of concern at the level of II (stage of personal); four teachers ( $8 \%$ ) have a stage of concern at level of III (stage of management); eight teachers (16\%) have a stage of concern at the level of IV ( consequence); ten teachers ( $20 \%)$ have a stage of concern at the level $\mathrm{V}$ (collaboration) and three teachers (6\%) have stage of concern at the level of VI (refocusing).
\end{abstract}

Keyword-Awareness, Innovations, Curriculum, Stage of Concern, Lesson Plan

\section{INTRODUCTION}

The teacher is a professional position. Of course, in carrying out his duties, he should act and work in a professional manner in accordance tasks and duties mandated to him. Based on the results of a survey conducted in the form of observations and interviews with teachers in elementary schools vary greatly in carrying out its duties and responsibilities as educators. Most of them have a high commitment to the tasks and duties mandated to him, but others of them merely meet administrative requirements, even some others just appear to carry out the task. Reference [1] Article 20 states that teachers are obliged to plan a learning, implementing quality learning process, as well as assess and evaluate learning outcomes. Expressions of this legislation clearly indicate that one of the tasks the teachers is to plan a lesson plan. Based on this rule, because it was stated as a liability, should a teacher have a high concern on his job in the learning plan. Based on the results of the survey in April 2016 the level of concern of teachers to their obligations in constructing lesson plans varies greatly. The individual planning a lesson plan, there are some teachers who diligently to think, plan and develop what should be done in implementing the learning. Most of them were taken from the internet and then slightly modify it. There are also some who just mimic or copy the lesson plan as it exists on the internet as a whole without modifying it, do not even know what was in the lesson plans are taken, which is important in the administration has lesson plans, and there are even worse where they carry out learning without lesson plans, he did not know what to do in the classroom, which is important seems to come in the classroom.

Results of research conducted by the Ministry of Education and Culture in 2012 at the State Primary School teachers indicate that teachers eligible to teach only $42.2 \%$, the private elementary school teachers eligible to teach only $39.5 \%$, junior high school teachers appropriate and feasible teach only $49.4 \%$ and $31.7 \%$ is not worth teaching, it is not appropriate and feasible $10.7 \%$, inappropriate and unfit to teach $9.0 \%$ of the total number of teachers 283715 teachers as in [2]. Results of Research University of Texas Research and Development Center of the behavior of educators is obtained about the level of concern and application in innovation, as in [3], [4], [5]. Based on these two studies implicitly signaled to us that the behavior of teachers is very varied and graded in doing something. The problem is how to measure the behavior of the varied and graded.

Reference [6] says that the progress of new programs is often measured by how well they are being executed. This approach tends to ignore a critical actor-the person charged with implementing the innovation. The Stages of Concern process helps keep the people doing the work at the center of the change process. Using the Stages of Concern, education leaders can assess and respond to the worries, attitudes, and perceptions of staff as they deal with the challenges of changing the way they work.

The Stages of Concern consists of and describes seven categories of possible concerns related to an innovation of their work, included in this is an innovation in their constructing of a lesson plan. Teachers who are in the earlier stages of a change process will likely have more self-focused concerns, such as worries about whether they can learn a new lesson plan or how it will affect their job performance. As individuals become more comfortable with and skilled in using an innovation of constructing a lesson plan, their concerns shift to focus on broader impacts, such as how the initiative will affect their students or their working relationships with colleagues.

Reference [7] The 7 stages of teachers' concern as following. Stage 0: Awareness. Litle concern about an involvement of the innovation global implications and possible alternative. Stage I: Informational. A general awareness of the innovation and interest in learning more detail about it is indicated. The person seems to be unworried about himself/herself in relation to the innovation. She/he is interested in substantive aspects of the innovation in a selfless manner such as general characteristics, effects of the innovation in a selfless manner such as general 
characteristics, effects, and requirements for use. Stage II: Personal. The individual is uncertain about the demands of the innovation, his/her inadequacy to meet those demands and his/her role in the innovation. This includes analysis of his/her role in relation to the reward structure of the organization, decision constructing, and consideration of potential conflicts with existing structures of personal commitment. Finacial or status implication of the program for self and colleagues may also be reflected. Stage III: Management. Attention is focused on the processes and tasks of using the innovation and the best use of information and resources. Issues related to efficiency, organizing, managing, scheduling and time demands are utmost. Stage IV: Consequence. Attention focused on the impact of the innovation on a student in his/her immediate sphere of influence. The focus is on a relevance of the innovation for the student, evaluation of student outcomes, including performance and competencies, and changes needed to increase student outcomes. Stage V: Collaboration. The focus is on coordination and cooperation with others regarding the use of the innovation. Stage VI: Refocusing. The focus is on an exploration of more universal benefits from the innovation, including the possibility of major changes or replacement with a more powerful alternative. An individual has definite ideas about alternatives to the procedure existing form of the innovation. These stages of concern have been simplified by [8] in the form of typical expressions of concern about an innovation as following.

TABLE I. STAGES OF CONCERN: TYPICAL EXPRESSIONS OF CONCERN ABOUT AN INNOVATION

\begin{tabular}{|l|l|}
\hline \multicolumn{1}{|c|}{ Stage of concern } & \multicolumn{1}{c|}{ Expression of Concern } \\
\hline 6. Refocusing & $\begin{array}{l}\text { I have some ideas about something that would } \\
\text { work even better. }\end{array}$ \\
\hline 5. Collaboration & $\begin{array}{l}\text { I am concerned about relating what I am doing } \\
\text { with what my co-workers are doing. }\end{array}$ \\
\hline 4. Consequence & How is my use affecting clients? \\
\hline 3. Management & $\begin{array}{l}\text { I seem to be spending all of my time getting } \\
\text { materials ready. }\end{array}$ \\
\hline 2. Personal & How will using it affect me? \\
\hline 1. Informational & I would like to know more about it. \\
\hline 0. Awareness & I am not concerned about it. \\
\hline
\end{tabular}

Based on the gap between what should be done by a teacher with the phenomenon of reality that happened, the researchers wanted to know the truth of how the level of concern of teachers on duty as an educator in constructing of their lesson plan. o assess the degree of concern of primary school teachers in constructing a lesson plan, the research team applied seven levels of awareness levels as proposed by Miller, G.W. John P., and Seller, Wayne 1985 and simplified by Wenfeng Wang in 2014.

\section{METHOD}

This research using descriptive research approach as in [9], the population in this study are primary teachers amounting to 500 teachers. Sampling the research using random sampling which amounted to $10 \%$ of the population. Data on the learning plan collected through inventory techniques, while data on the identity of elementary school teachers gathered through technical documentation. Grating inventory is on the aspects that must a universal in the planning of learning. These aspects include: (a) mapping core competencies in the curriculum, (b) creation of a network theme core competencies, (c) syllabus, (d) the constructing of the lesson plan, and (e) the manufacture student activity sheet. Inventory arranged in a hierarchy of concern at the levels of awareness, information, personal concerns, management, consequence, collaboration, and refocusing. Once the instruments (inventory items) composed and performed judgment by experts, then tested and analyzed to determine the validity and reliability of the instrument. Instruments which have sought the validity and reliability, are used by researchers to collect data about the stages of concern of teachers in preparing lesson plans.

\section{RESULTS AND DISCUSSION}

Based on the results of the instrument inventory is deployed, data showed the level of concern of teachers in preparing lesson plans as follows: $16 \%$ of teachers ( 8 teachers) at levels of 0 (the stage of awareness), 9 teachers $19 \%$ of teachers (9 teachers) at the level of the 1 st (stage of information); $16 \%$ of teachers ( 8 teachers) at level 2 (personal), $8 \%$ of teachers ( 4 teachers) at the level to 3 (stage of management), 16\% teachers ( 8 teachers) at the level 4 (stage of consequence); $20 \%$ of teachers (10 teachers) at the level to 5 (collaboration) and $6 \%$ of teachers (3 teachers) at the level to 6 (refocusing).

Based on the Data show that $16 \%$ of elementary teachers are not concerned about constructing a lesson plan when they want to teach. They come to school to teach directly with no direction on where students will be taken, without thinking and of whether after the learning process of their students acquire the knowledge, skills, and attitudes of certain expected or not. They only think of which is already coming to school teaching, which is already seen by other teachers and the headmaster is already in the classroom. From the number of teachers, only $19 \%$ of them who would like to know more about how to construct a lesson plan. They are a little more willing to read and or ask it to others in order to obtain information about how to plan for learning than which are in the stages of awareness. There are 18 $\%$ who are in the stage of personal. The teachers who are in these stages have a higher concern on constructing a lesson that they are in an informational stage in that they have questioned theirs 'how will use a lesson plan affect theirs? for examples influencing their career. In this case, they have already thought that the constructing a lesson plan will have a tendency to affect benefits for them. The result of this research has also indicated that there are $8 \%$ in stage of management. The ones who are in this stages have already thought to spend their time for managing materials related to constructing a lesson plan ready. So the lesson plan made is ready to use reaching their goal of teachinglearning. There are $16 \%$ of teachers are on the stage of consequences in constructing a lesson plan. The one who is on the stage of concern has thought it further than ones who are on the stage of management. They do not only think of constructing a lesson plan ready to use, but they have an expression of concern "how is my use of a lesson plan affecting their clients or their student in the long run?" The result of this study also indicate that there are $20 \%$ of teachers are on the stage of collaboration. It means that they already have an expression of concerns "I am concerned about relating what I am doing with what my co-workers are doing". They have already compared to each other to make their job better achieved. The highest stage 
of concern is the stage of refocusing concern. In this stage, teachers are not only compared to what they are doing with their co-workers are doing to improve their achievement of work but they have much effort to have ideas to improve their work or teaching more and more perfect. In their expression of concern appear as "I have some ideas about something that would work even better and better".

\section{CONCLUSION}

Drawing on Concerns-Based Adoption Model, this study has examined the teachers' stages of concerns of the constructing a lesson plan in Bengkulu. The characteristics of teachers'stage of concern of the constructing a lesson plan as following: $16 \%$ of teachers at levels of 0 (the stage of awareness), $9 \%$ of teachers at the level of the 1st (stage of information); $16 \%$ of teachers at level 2 (personal), $8 \%$ of teachers at the level to 3 (stage of management), $16 \%$ teachers at the level 4 (stage of consequence); $20 \%$ of teachers at the level to 5 (collaboration) and $6 \%$ of teachers at the level to 6 (refocusing). The result of the study has been an indication that only a few of teachers $(6 \%$ of teachers) who have the highest stage of concern, the stage of refocusing. Most of the teachers are only think of constructing a lesson as the most important thing is a lesson plan, they are less thinking of it as an effort to improve their achievement in the teaching-learning process. And even $16 \%$ of teachers are not concerned about constructing a lesson plan when they want to make their students learning.

\section{ACKNOWLEDGEMENTS}

The author wishes to thank for the Post Graduate Program in Educational Technology, Faculty of Teacher Training and Education Bengkulu University, which provided a fund for this research project. Secondly, we would like to thank all of the head of the research and social service Board Bengkulu University who coordinated and facilitated administration of this research project. Lastly, we would like to thank the heads of elementary schools, teachers, support staff, and students in Bengkulu Municipality, who helped us to develop and complete this project through their participation and cooperation.

\section{REFERENCES}

[1] The Law of the Republic of Indonesia Number 14 The year 2005 on Teachers and Lecturers

[2] The Ministry of Education and Culture (2012). Results of the Research from the Board of Education and Culture Indonesia, Jakarta: Department of Elementary and Secondary Education

[3] George A. A, Hall, G. E. \& Rutherford, W. L. (1977). Research on Curriculum and Instruction Implementation. Review of Educational Research. 47,2:335-397.

[4] Hall, G.E. \& Louck, F. (1978). Teachers' Concerns as a Basic for Facilitating and Personalizing Staff Development. Teachers College Record. 80. (1), 36-53.

[5] Jackson, Philip W. (1994). Handbook of Research and Curriculum, Macmillan Publishing Company: NewYork.

[6] Hall, G. E., Dirksen, D. J., \& George, A. A. (2006). Measuring implementation in schools: Levels of Use. Austin, TX: SEDL. Available from http://www.sedl.org /pubs/catalog/items/cbam18.html

[7] Miller, G.W. John P. and Seller, Wayne. (1985). Curriculum Perspectives and Practice, Longman: New York \& London.
[8] Wang, Wenfeng (2014). Teachers' Stages of Concern and Levels of Use of a Curriculum Innovation in China: A Case Study. International Journal of English Language Teaching Vol. 1, No. 1; p 22-31

[9] Issac, Stephen \& Michael, William, B. (1982). Handbook in Research and Evaluation, Edits Publisher: California. 